\title{
A Tension in the Strong Program: the Relation between the Rational and the Social
}

\author{
Shahram Shahryari
}

The Department of Science Studies, Iranian Institute of Philosophy, Tehran, Iran shshahryari@irip.ac.ir

shshahryari@gmail.com

https://orcid.org/0000-0001-5398-5614

\begin{abstract}
Advocating a sociological explanation of scientific knowledge, David Bloor protests against the adherents of the autonomy of knowledge, i.e. those who asymmetrically explain the credibility of theories in the history of science. These philosophers and historians regard the credibility of true and rational theories due to their proper reasons, while accounting for the acceptance of false or irrational beliefs by citing social causes. Bloor assumes that the credibility of all beliefs is socially influenced, and therefore considers all in need of sociological explanation. To substantiate this claim, he argues that all epistemic factors that are appealed to in explaining true or rational beliefs are really social. However, this argument aligns rational entities with social factors, and thus, undermines the ground of this division. Therefore, his prior complaint of the autonomy of knowledge would be invalidated. Hence, there is a conflict between Bloor's objection to the asymmetrical explanation of scientific theories and his account of the social construction of epistemic reasons. In this paper, we reveal this concealed conflict and attempt to suggest ways to resolve it.
\end{abstract}

Keywords The symmetry principle; Substance monism; Social constructivism; Strong Program 


\section{Introduction}

Social constructivists proclaim that the truth, rationality, and success of all beliefs, including scientific theories, are socially built. A prominent approach to constructivism which focuses particularly on the social study of science is David Bloor's 'Strong Program'. Bloor sets out powerful arguments in defense of the social construction of epistemic factors and rational attributes. His arguments are widely regarded as demonstrating that the rational and the social are the same (Kusch 2000, 31-2; Kemp 2003, 312-3; and Seidel 2014, 83) - the view we refer to as the monistic conception of this relation or substance monism.

Another kind of monism appears in the most famous principle of the Strong Program, namely 'the principle of symmetry'. ${ }^{1}$ This principle requires that all beliefs, no matter what their value is, should be symmetrically explained, i.e. by causes of one kind (Bloor 1991 [1976], 7-9). As a result, Bloor stands against the dualism acknowledged by scholars who explain true or rational beliefs by epistemic reasons and false or irrational beliefs sociologically. He complains about this asymmetrical explanation of science being biased and unscientific (ibid, 13).

The monistic picture reinforces the symmetry principle in one way; since it indicates that even arguments themselves are made up of social factors, therefore not only non-rational beliefs but also rational beliefs need sociological explanation. However, substance monism unexpectedly makes Bloor's complaint against asymmetrical explanations unfounded in another way; for if reasons and arguments are also social, explaining true or rational scientific beliefs by reasons and false or non-rational ones by social factors could not be considered asymmetrical.

\footnotetext{
1 At least once the symmetrical explanation is also called "monism" (Barnes and Boor 1982, 25). Bloor therefore speaks of two monisms: explanatory monism and substance monism. However, in order to avoid the confusion of the two, by "monism" in the rest of the paper, we only mean the second idea.
} 
Opponents and supporters of the program have discussed in detail the principle of symmetry, substance monism, and the beneficial relation of it to symmetry; however, their detrimental relation has been mostly overlooked. In this paper, we would deal with the negative side of the relation and illustrate what limitations substance monism places on the Strong Program and Bloor's criticism of the asymmetrical explanation of scientific theories. Although this paper deals exclusively with the Strong Program as stated in Bloor's work, the result can also provide insight into other constructivist approaches to knowledge.

The rest of this paper is structured as follows: in section 2, we introduce the principle of symmetry and Bloor's complaint against asymmetrical explanations. In section 3, we present Bloor's attitude toward the social construction of epistemic factors and briefly summarize his arguments. In section 4 , we demonstrate why the identity of the social and the rational makes Bloor's complaint groundless and creates a conflict in the program. And in section 5, we suggest ways to resolve this challenge consistent with the Strong Program's core insights.

\section{Bloor's Complaint Submission}

The Strong Program, as Bloor presents it, seeks to explain all scientific beliefs with social causes, regardless of how the analysts evaluate them. To this end, Bloor introduces four methodological principles for explaining knowledge, including scientific knowledge, according to which sociological explanations must be causal, neutral, symmetrical, and reflexive. Therefore, the sociological explanations of science must, respectively, address the causes of belief creation, encompass all kinds of beliefs, apply the same types of causes to beliefs of any value, and be applicable to the sociology itself (Bloor 1991, 7).

The most significant and controversial tenet of the Strong Program is the symmetry principle, according to which the same type(s) of causes must explain, say, rational beliefs 
and irrational beliefs. ${ }^{2}$ Bloor notes that he does not mean that the same causes explain all beliefs, rather he affirms that the same kinds of causes should explain them (Bloor 2004, 937; 2011, 6\&402).

Therefore, we can define symmetrical explanations and asymmetrical ones as follows:

(I) An explanation is symmetrical if it explains rational beliefs and irrational beliefs with causes of the same kind and, similarly, asymmetrical explanations involve those explanations that cite different types of causes for accepting rational beliefs and irrational ones.

There is a similar symmetry between the explanation of true beliefs and false ones, as well as the explanation of successful beliefs and unsuccessful ones (ibid, 7-8).

The Strong Program, says Bloor, contrasts with the dominant view of historians, philosophers and even sociologists who divide beliefs in terms of their evaluation, and consider different explanations for each category. They regard the credibility of true, rational, and successful beliefs as the result of reasons that demonstrate their truth, rationality, and success. On the contrary, why scientists sometimes accept false, irrational or unsuccessful beliefs is explained by other factors that made them believable - for instance, causes related to economic pressures, political considerations, religious and nationalist prejudices (Bloor 1991, 8-9).

Imre Lakatos epitomizes this attitude when he assesses the value of competing scientific methodologies in terms of how they can explain the great successes of the history of science. In his opinion, each methodology reconstructs the history of science rationally and considers

\footnotetext{
${ }^{2}$ Although the principle of symmetry is expressed in many different and equivocal ways in Bloor's works, the above version presents its standard and more common form (see: Bloor 1991, 7; 2004, 937; 2011, 6\&402). Larry Laudan (1981, 182), Tim Lewens $(2005,564)$ and Jeff Kochan (2008, 22 \& 2010, 129), among others, have also considered the same formulation as the principle of symmetry.
} 
some other scientific events that are not consistent with its methodological principles the irrational periods of the history of science. Lakatos asserts that in every rational reconstruction of science there will be non-rational parts, which psychological and social causes can explain. He calls the rational part 'the internal history', and the non-rational part 'the external history' of science. Only when no rational reconstruction of them is possible, these causal explanations are leveled (Lakatos 1989 [1971], 118-20).

Bloor sometimes refers to this approach to the explanation of scientific theories as 'the autonomy of knowledge' (Bloor 1991, 8) or 'the teleological view' (ibid, 11) and considers it "the extreme form of asymmetry" (ibid, 13). Accordingly, whether beliefs with different values are explained by causes of the same kind draws a decisive line that makes the explanations of the Strong Program symmetrical and separates Bloor's approach in explaining beliefs from that of the so-called rationalists or adherents of the autonomy of knowledge who first evaluate beliefs, and then explain beliefs that are positively valued, different from beliefs that are valued negatively. So, "[t]he general structure of these explanations", says Bloor, "stands out clearly":

They all divide behaviour or belief into two types: right and wrong, true or false, rational or irrational. They then invoke sociological or psychological causes to explain the negative side of the division. Such causes explain error, limitation and deviation. The positive side of the evaluative divide is quite different. Here logic, rationality and truth appear to be their own explanation. Here psycho-social causes do not need to be invoked (ibid, 9).

Hereupon, one can comprehensibly see that:

(II) Explaining true or rational beliefs with epistemic reasons and false or irrational beliefs with social causes is an asymmetrical explanation. 
Although Bloor accepts (II), he constantly objects to explaining scientific theories asymmetrically. This kind of explanation is found guilty of betrayal to scientific values and the approach of empirical sciences (ibid, 13); since "[i]f explanation is allowed to hinge on prior evaluations" Bloor asserts "then the causal processes that are thought to operate in the world will come to reflect the pattern of these evaluations"; therefore, it loses the moral impartiality required by scientific research (ibid, 13). Thus, it can be said that while teleological explanations of scientific knowledge presuppose its correctness and regard it as the criterion of distinction in explanation, the Strong Program's symmetrical explanations stems from the awareness that due to the defeasibility of our current theories, they cannot be a reliable criterion for the type of explanation. Therefore, the rationale behind the symmetry principle is that sociologists, as analysts of scientific knowledge, should "separate the world from the actor's description"; so they do not take for granted what is the topic of their inquiry (Bloor 1999, 93).

In short, Bloor's complaint to advocates of the autonomy of knowledge is that their explanation of scientific knowledge is discriminatory: due to their prejudices, they utilize different kinds of causes to explain beliefs. To put it more precisely, Bloor's criticism is not why they regard rational and social explanations as two different kinds ${ }^{3}$ rather, it is why, by their assumptions, they use two different types of cause, i.e. rational type and social type, to explain scientific theories.

\section{Bloor's View on the Social Construction of Epistemic Reasons}

To establish the symmetry principle in sociological studies of science, Bloor puts forward strong arguments to demonstrate that social causes and factors play an undeniable role in the credibility of all beliefs, even rationally justified ones, and therefore all beliefs require

\footnotetext{
${ }^{3}$ There are a few exceptions in his more recent works that we will address.
} 
sociological explanation. His arguments indicate that social factors play a constructive role for epistemic reasons or rational and logical principles. So, our rationality, accordingly, is made up or constituted or constructed of social factors. That is to say, "epistemic factors are really social factors" (Bloor 1984, 297).

According to Bloor, reasons and inferences are not understandable "without appreciating their dependence on patterns of training, conventions of use, and the precise historical circumstances that attend their employment" (Bloor 1984, 298). Bloor adds "[t]here is nothing else which, so to speak, lies behind our reasoning, to which our rational steps must correspond or have reference" (ibid, 298). It follows that the rationality of a belief, in the sense of believing it for reason, underpins the influence of social factors in its credibility. We will touch upon his arguments below to illustrate how, in his view, social factors construct rational or epistemic factors.

One of Bloor's most important arguments for revealing the constitutive role of social factors in rational reasoning draws on the underdetermination of theory by evidence. On this ground, he argues that the evidence never specifies the theory and any amount of empirical evidence is consistent with several theories. He (with Barry Barnes) argues that evidencing reasons are, above all, socially variable; since, "something is only evidence for something else when set in the context of assumptions which give it meaning..." (Barnes and Bloor 1982, 28-9). Therefore, it is only by attaching the scientists' assumptions that evidence can determine one of the rival theories as more empirically supported. These assumptions are rooted in scientists' interests (Bloor 1981, 203-4). Further, as to what is considered evidence, there is no rule or obvious way to decide, nor any higher court than the consensus of the scientific community (Bloor 2004, 931).

The same is true of what are called 'formal' or 'extra-empirical' criteria for the best explanation - simplicity, consistency and the like. There is philosophical disagreement 
surrounding these criteria as well as how they are discerned. From the sociologist's point of view, choosing a scientist's criterion by is not the end of the story; since this decision itself demands an explanation too: why is this criterion espoused and not another? It is only the consensus of experts, as a social causal factor, that will give the definitive answer to this question (Bloor 1981, 201-2).

Likewise, any theory can be sustained by adding some appropriate auxiliary assumptions. Only the tradition that the scientist operates within "limits the acceptable interpretations which can be put on the facts of experience" and thereby defines what normal science is. Therefore, only within a tradition, scientists can decide whether the occurrence of an unforeseen phenomenon crucially defeats the theory in question (Bloor 1981, 202). As a result, "credibility only makes sense when the scientist's behaviour is set in its social context" (Bloor 2004, 921-3).

Thus, although Bloor often disregards the various divisions of the underdetermination thesis and does not refer to recent discussions about it, his points are sufficiently impressive. In spite of some criticisms (Laudan 1990, 289-291), Bloor neither considers underdetermination per se as implying the presence of social factors in the credibility of beliefs, nor reduces rationality to deductive logic, nor interrupts the connection between beliefs and evidence. He, instead, argues for the sociality of the evidential relation and demonstrates that scientists' criteria for inferring the best explanation and also their standards for confining the scope of plausible theories are social phenomena as well. The presence of the social factors in rational beliefs is more clearly seen in another argument, which sometimes traces the argument from underdetermination.

This argument resides in a theory called 'finitism', according to which words do not have predetermined meanings; meanings are created through a process of collective decision- 
making. This unstable and continued-creation ${ }^{4}$ collective process provides the norm that determines what is right and wrong for future cases. Consider when a scientist is supposed to follow a rule. The limited cases of following the rule given to them cannot determine how they should act on the new case in the same way; since nothing in all respects resembles anything else. The degree of similarity and its adequacy and relevance needs to be judged by criteria which are generally accepted. So it is the users' consensus that determines how to follow the rule in the new cases. This indicates that the only fact that determines the correct way to follow the rule is social reality (Barnes et al. 1996, 55; Bloor 1997, 36-7; 2011, 4079).

What is said about following the rule, also applies to whether or not a concept applies to an object. When categorizing objects, there is no fact outside the community that reveals the truth or falsity of the classification. Also, is determined wholly by the than consensus among scientists that appears throughout their debates, e.g. in textbook tables, or the manner in which qualified individuals practice (Bloor 2007, 272; 2008, 21f).

These convey that scientists only learn, accept and apply these assumptions by implication. So in their view, these implicit presuppositions constitute part of the scientific rationality that they have subscribed to. Nevertheless, from sociologist's point of view, the admission of these draws on the pursuit of the community's goals, interests, and so on. Therefore, what the actor considers the criteria of rationality is, for the analyst, a sign of the presence of social interests.

The conclusion of all these remarks is not that scientific beliefs are deprived of good reasons or any method is as plausible as any other method, but that the rationality of scientific beliefs is configured by social factors. Bloor interprets this relation by saying that rational causes are "really nothing more than a species of social causes". This means that the "dualism

\footnotetext{
${ }^{4}$ The term is borrowed from Kusch $(2002,200-1)$.
} 
of rational and sociological causes, which allegedly compete or alternate with one another, or supplement one another" is spurious. The end result is that "[t]here will be no duality of rational and social causes". In contrast, a monist view of the relation between the rational and the social is substantiated (Bloor 2011, 406). So Bloor says:

Supporters of the Strong Programme have always opposed the assumption that the rational and the social are fundamentally different in their nature.... The programme was formulated in opposition to those who would erect a fundamental dualism of the rational and the social. In this sense it expresses a form of monism... (Bloor 2007, 223).

Consequently, Bloor again attributes those like Karl Mannheim, Robert Merton, Imre Lakatos, and Larry Laudan to a tradition that espouses a dualism of the rational and the social, or the distinction between the internal and external history of science. He runs to the contrary:

All of the different developments in the sociology of scientific knowledge, whether contemporary laboratory studies, or sociologically informed historical work, have been devoted to overcoming this dualistic, indeed Manichean, conception of knowledge (Bloor 2004, 920).

In the relevant literature, this view is referred to as 'monism' or 'identity of the rational and the social'. 5 Martin Kusch, a contributor to the sociology of scientific knowledge, acknowledges this monism and expounds it. He Calls the claim that "all 'rational entities' (arguments, theories, reasons) are social entities” sociologism (Kusch 1999, 177, 182-3; 2000 ix \& 30), and argues that sociologism can be interpreted in different ways. He declares that in a personal communication, Bloor has committed himself to reductive sociologism that draws

\footnotetext{
${ }^{5}$ One should be aware that type-identity is at stake here, not token-identity. For, as we have already seen in section 2, Bloor denies explicitly the token-identity even for social causes themselves.
} 
upon the assumption that every kind of rational entity is identical with a kind of social being. Socio-rational laws express the identity between these two kinds of identities, e.g. arguments of type 'A' are acceptable in a social structure of type 'S' (Kusch 1999, 183-4; 2000, 31-2). However, Kusch suggests that Bloor's work is best treated as part and parcel of anomalous sociologism. This view conceptualizes the rational as supervening on the social, in the sense that it identifies historically situated rational elements with historically situated social institutions while, denying the possibility of strict ratio-social (type-type) laws (Kusch 1999, $184-5 ; 2000,32)$.

In a similar vein, Stephen Kemp interprets the relation between social interests and success of science in the Strong Program in the same way and refers to it by 'unification' and 'monism'. He mainly focuses on the Strong Program's theory of classification, i.e. finitism, to demonstrate how the pursuit of interests is seen in this program as an instrumental success (Kemp 2003). Although speaking of the success of science, his discussion is very close to the social construction of rationality; that is how finitism provides evidence for the theory's correspondence with reality or prevents its rejection in the face of unexpected phenomena.

Markus Seidel, a staunch critic of the Strong Program, has a similar understanding of the relation between the social and the rational, after a discussion of how social factors constitute rational arguments conforming to the Strong Program (Seidel 2014, 83-5). He quotes part of Bloor's statement in reply to Ernan McMullin:

I wish to challenge this picture by arguing that epistemic factors are really social factors. The dichotomy that McMullin uses to give structure to his scheme seems to me a false one (Bloor 1984, 297).

Seidel's discussion leads to the view that in the Strong Program, epistemic factors are not replaced by social factors but are themselves social factors (Seidel 2014, 83). 
Kusch, Kemp, and Seidel's discussions of Bloor's view demonstrates that rational factors and social causes are united and unified. We can put this monistic picture of their relation in a nutshell:

(III) The social and the rational are entities of the same type.

In the end, nevertheless, we will say that another interpretation is also possible for the construction of the rational by the social, which, although it may not be easy to reconcile with some of Bloor's remarks, is at least free from the problem which we shall now raise.

\section{The Emergence of Conflict}

So far we have said that, first, Bloor complains about the asymmetrical explanation of scientific knowledge; that is, he denies that scientific rational beliefs are explained by reasons, and other beliefs by social causes. In addition, he, along with associates such as Kusch, considers the epistemic factors, including evidence, arguments and discussions among scientists to be social. The latter provides the basis for the former meaning that social factors are also productive in shaping in the credibility of well-justified beliefs. Thus, the same type of cause, i.e. social cause, symmetrically explains all beliefs.

The second point, however, has a dire consequence: it makes Bloor's protest against the advocates of the autonomy of knowledge meaningless. He attacked them for their asymmetrical explanations: explaining true or rational beliefs by epistemic reasons, while attributing false or irrational beliefs to social factors; thereby Bloor invited these analysts to symmetrical explanations. Nonetheless, it now turns out that those so-called epistemic reasons fall into the category of the social, and therefore rational and social entities are of the same kind. So the question arises, what the objection is to advocates of the autonomy of knowledge and to their historiography of science. Although they explain rational scientific beliefs by epistemic reasons and other beliefs by social causes, since the rational and the 
social are ultimately the same, they have effectively explained both kinds of beliefs with the very same type of causes: social causes. Stated differently, the identity of the rational and the social challenges Bloor's previous claim that rational and social causes are typically different. Thus, in the light of monistic understanding of the above relation, his complaint of asymmetrical explanation seems to be no longer grounded.

But the problem is not only that Bloor's protest is unfounded, the problem is far greater; by admitting that rational causes are social causes, a conflict emerges between two of his claims. For, on the one hand, Bloor considers the rational and the social two different types (and precisely for this reason, he calls the explanations based on them asymmetrical), and on the other hand, he considers them of the same type. The first consideration is obviously at odds with the second one. Notice that, unfortunately, none of Kusch's different versions of sociologism can solve the problem either; for in all of them, in spite of the difference in the relation between the rational and the social, these two entities were conceived substantively one and the same by definition. Therefore, although sociologism of one sort or another may accurately describe Bloor's views on the relation of the rational and the social, his objection to the asymmetrical explanation calls for a substantive distinction between the two.

To make it clearer, let us formulate the conflict that appeared in Bloor's claims in line with the results obtained in the previous sections:

(I) Asymmetrical explanations are those explanations that involve different types of causes for accepting rational beliefs and irrational ones. (And similarly, symmetrical explanations are those explanations that include causes of one type for the credibility of rational beliefs and irrational ones.)

(II) Explaining true or rational beliefs with rational causes and false or irrational beliefs with social causes is an asymmetrical explanation.

(III) Social causes and rational causes are entities of the same type. 
From (I) and (II) it follows deductively that:

(IV) Explaining true or rational beliefs with rational causes and false or irrational beliefs with social causes involves different types of causes.

This means:

(V) Social causes and rational causes are different types of entities.

However, (III) and (V) patently contradict each other.

Contrary to what one might think, both premises of the deduction, (I) and (II), are Bloor's own statements and there is no confusion of Bloor's claims with that of his opponents'. Since the argument consisting of (I) and (II) simply expresses Bloor's view of asymmetry and never commits him to asymmetrical explanations, any doubts about the veracity of the premises are eliminated. As for the form of the argument, it is clearly a valid deduction. So the argument is undoubtedly sound.

The second possible criticism is that just because two explanations are fundamentally different does not mean that the causes cited are also of two different types. Therefore, the critique continues, since sociological and rational explanations are different in type does not require that social causes and rational causes are two different types. So there is no conflict between the identity of the rational and the social, and regarding explanations based on them as different kinds of explanation.

This objection also seems to rest on a misunderstanding. The revocation of the alleged requirement may be correct, but it has nothing to do with our argument. True, just because social and rational explanations are two different kinds, does not contradict Bloor's another claim that the social and the rational are of the same kind. However, here is another premise left out by the critic, and that is Bloor's assertion's that asymmetrical explanations are those that cite different types of causes for theories evaluated differently (recall I). That the asymmetrical explanations are based on different types of causes - and therefore the social 
and the rational are of two different kinds - thus directly derive from Bloor's own remarks and is not presumed in our argument. So the conflict in question really exists.

As the third objection to the argument, one may resort to the idea of finitism saying that categorization is the subject of experts' consensus and therefore varies depending on the culture and context. Put differently, classifying things as rational or social is a matter of contingency, not necessity. So, the critic goes on, whether social and rational entities are of the same type has no single universal answer. In one area they may be considered to be of the same type by the experts' agreement, and in another they may not be due to a different agreement. In any case, there is no context-independent answer to this question.

Alas, considering that this conflict is the result of a deduction, both premises of which are Bloor's own remarks makes this defense frustrating. In other terms, no matter where he came up with the criteria for this division, it is Bloor himself that sees the social and the rational as different types - this is when he calls explanations based on them asymmetrical (e.g. Bloor 2011: 400-1) - but simultaneously regards them as the same type - where he speaks of the social construction of knowledge (e.g. ibid, 409-10).

Finally, one may wonder how a methodological principle, the symmetry tenet, might conflict with an ontological position, such as substance monism. These are on two different levels and talk about two different categories of things: while the former speaks of the method of sociological explanation, the latter speaks of the entities that exist in the world. So, continues the critic, despite the soundness of the argument, there must be something wrong here.

But this response cannot resist the argument either; since it relies on confusion. To be more precise, this is not the symmetry principle itself which conflicts with substance monism, but the presuppositions underlying this principle; i.e. the relation it expresses between sociological explanations and rational ones. Let us return to the formulation of the argument: 
(I) and (II) are in conflict with (III); (III) expresses substance monism, but (I) and (II) do not represent the symmetry principle; they do not state any methodological instructions to the effect that the explanation should be symmetrical. Instead, they assert a dichotomy between two types of entities. As a result, here an ontological proposition about the relation of the rational to the social contradicts another ontological proposition in that same regard, not a methodological principle on how to explain scientific knowledge. Hence, the critic's surprise is misplaced.

\section{Some Possible Ways to Resolve the Conflict}

Although we think our argument for this conflict is conclusive, it does not mean that it fundamentally destroys the Strong Program. There may still be some different comprehension of the relation between the rational and the social consistent with Bloor's perception of asymmetry or there may be some other solutions that, despite some minor variations in the face of this challenge, retain the core insights of the program. In this section, we will discuss some possible solutions.

The first proposal that may resolve this conflict is to remove one of the parties in terms of Bloor's intellectual development. For this purpose, one may claim that his thinking has undergone some changes, so that one of the two ideas, i.e. the asymmetry of rational causes and social causes or their substantive monism, has been abandoned. This claim is not entirely irrelevant. Although Bloor himself never explicitly acknowledged such a conversion, following the historical course of his thought reveals that he has changed his mind over time. In his early works, Bloor objects to the asymmetry of the rational and the social, but in more recent works, he says his protest has always been against the disparity between the two. For instance, he states that philosophers of science, like Lakatos and Laudan, "treat rational processes as fundamentally distinct from the nexus of sociopsychological causes" (Bloor 2011, 488; Emphasis added). In some of his writings, including the one quoted earlier, Bloor 
says that the Strong Program has "always opposed the assumption that the rational and the social are fundamentally different in their nature" and thus, the program is "formulated in opposition to those who would erect a fundamental dualism of the rational and the social" (Bloor 2007, 223). These quotations may suggest that Bloor abandoned his earlier claim that rational explanations and sociological explanations are asymmetrical, not the principle of symmetry itself. In so doing, he can retain premise (I) and reject premise (II).

But this proposal faces two problems: First, by admitting this conversion the question arises as to what is the 'asymmetrical explanation' Bloor continues to speak out against in his later writings. For instance, when he says that the scientific controversy between the British and the Germans can be explained both symmetrically and asymmetrically $(2011,401)$, what may he mean by 'asymmetrical explanation'?

Second, according to this method of conflict resolution, the valuation-based historiography that has always been attacked by Bloor and his colleagues must also be approved; since in the last analysis, it also explains both categories of beliefs, i.e. rational and irrational, by the same kind of causes. Thus, for instance, Bloor's sociological account of the history of aircraft in both Germany and Britain in his Enigma of the Airfoil (2011) is as legitimate as a Whig account of this scientific controversy. Therefore, a Lakatoshian historian can also explain the rivalry between German and British scientists in terms of the distinction between internal and external history; so citing internal factors, the historian can say that the Germans admitted the circularity theory because of their superior rationality or having good reason, while explaining the British's acceptance of discontinuity theory by referring to some external elements - e.g. their economic pressures or implausible philosophical attitudes, etc. - that clouds their judgments. Note that these two problems are independent of each other: by rejecting (II), Bloor may still be able to make some sense of 'asymmetrical explanation', but this does not solve the problem of legitimizing it. 
To dispel these two objections, the best way is to modify premise (I) by saying that pursuant to Bloor's converted view, rational explanations and sociological explanations are not two different types but two different classes. The suggestion is that scientific explanation is hierarchical; sociological explanations and rational ones are at different levels. Therefore, Bloor's use of the term 'asymmetrical explanation' is still permissible and his critique of the historiography of the proponents of the autonomy of knowledge is as yet valid. Correspondingly, the asymmetry mentioned in Bloor's protest to rationalists must be understood in the sense that their explanation is multiple. So the rational and the social are considered, accordingly, two levels of one kind, not two different kinds - so, the first problem is warded off. Now, what is wrong with multiple explanations? The problem with this sort of explanation is that it does not reflect all aspects of the story; since one side (rational theories) is explained at an early stage and the other (irrational ones) by explanations at a deeper level. So there would be a kind of imbalance in the explanation. Another disadvantage of asymmetrical explanations - in the new sense that the explanation is multiple - is that it may insinuate that social causes and factors have no place in the credibility of true and rational beliefs. So the second objection is also prevented.

Another and more original way to evade the conflict, without changing the meaning of symmetry or abandoning the objection to rationalists, is to interpret the constructive relation between the social and the rational in a way other than their identity. To this end, Bloor's arguments for the construction of epistemic reasons by social factors must be taken to establish the view that social factors constitute epistemic factors partially, not totally. Consequently, these arguments, despite defending the presence of social factors in all beliefs and thus providing a justification for symmetrical explanation in the social studies of science, would not imply that epistemic reasons are entirely social factors. Therefore, by upholding the symmetry principle, the unity of the social and the rational can be discarded. 
All we needed to get rid of the mentioned conflict was an explanation that while maintaining the construction of the rational from the social preserves the type-difference between the two. Comprehending social causes as part of the construction of rational causes provides us with such an explanation. This picture, therefore, replaces (III) with another premise (III') in which:

(III') Social factors and rational factors are not entities of the same type.

Since the identity claim between the two is no more assumed in the new argument, conflict no longer lies in the premises. This solution also does not incur the costs and problems of the previous proposal: here, first, the construction of epistemic reasons with social causes is fully preserved; but since this does not imply their unification, the asymmetry of explanations based on the two factors also makes sense. Therefore, this interpretation, while rejecting the monistic picture, rehabilitates the Strong Program without impairing its underlying principles.

One might be tempted to say that Bloor expresses the same idea when he says: science "... cannot be called 'purely' sociological any more than it is 'purely' psychological or 'purely' a matter of grappling with the world" $(2011,402)$; or when he denies that the word 'strong' in the label of the 'Strong Program' is to mean that "nothing but society acts as a significant cause of belief and the material world and sensory-motor experience play no significant role" (2014, 405). This reservation has accompanied the Strong Program since its beginning; as introducing its four principles in Knowledge and Social Imagery, Bloor mentions under the principle of causality that "[n]aturally there will be other types of causes apart from social ones which will cooperate in bringing about belief' $(1991,7)$.

However, there are significant reasons we, we should resist this temptation. First, there is no doubt that Bloor contradicted himself by saying that the sociological explanation and the rational one are asymmetrical, while at the same time stating that epistemic reasons are nothing but a species of social factors or that they are of the same kind. Second, the subject 
under discussion is knowledge, not epistemic reasons; and these two are certainly not one thing. Bloor may believe that reasoning, justification, proof, etc., are all merely made up of social factors, but other things also play a role in the construction of knowledge. The conclusion is that what he says about the construction of knowledge is not necessarily correct about the construction of epistemic reasons. Taking this point into account, the Strong Program, as stated by Bloor, is committed to the view that social factors constitute rational factors utterly, and thus the two will be the same.

\section{Conclusion}

In this paper, we indicated that social constructivists' claim that rational or epistemic factors are really social has its limitations. Holding this view does not allow us to regard rational explanations and sociological causal explanations asymmetrical; i.e. based on two distinct types of cause. So we have to adjust at least one of these two theses.

If we preserve the identity of the rational and the social, then the claim of asymmetry between these two must either be abandoned or construed in a different sense; it could, for example, mean that these are explanations at two different levels, not different types of explanation. However, if we are to see rational explanations and sociological explanations as two different kinds, then the social construction of the rational should be construed in a sense other than their unity. Thus, one can say that social factors only partially constitute rational factors. Although Bloor is occasionally explicit in stating their unity, his arguments for constructing the rational from the social seem to be consistent with both partial and general readings. So, it is not unlikely that he had non-monistic understanding of the social construction of rationality and epistemic reasons, and those statements opposed to this interpretation are negligence or merely linguistic slips. With this being the case, Bloor must state what he considers to be involved in the construction of epistemic reasons other than 
social factors. Then the monistic interpretation, it could be said, stems mainly from the emphasis of his commentators, not his own.

Although incompatible with some of Bloor's own statements, these two amendments retain both symmetry as the most pivotal principle in the Strong Program, and the constitution of the rational by the social that underpins the symmetrical sociological explanation of beliefs.

\section{References}

Barnes, B. \& Bloor D. 1982. Relativism, Rationalism, and the Sociology of Knowledge. In Rationality and Relativism. Edited by M. Hollis and S. Lukes. Cambridge, MA: MIT Press. 21-74.

Barnes, B., Bloor, D. \& Henry J. 1996. Scientific Knowledge: A Sociological Analysis. Chicago: University of Chicago Press.

Bloor, D. 1981. The Strengths of the Strong Programme. Philosophy of the Social Sciences 11(2). 199-213.

Bloor, D. 1984. The Sociology of Reasons: Or Why Epistemic Factors are Really Social Factors. In Scientific Rationality: The Sociological Turn 25. 295-324.

Bloor, D. 1991. Knowledge and Social Imagery. 2th ed. Chicago, IL: University of Chicago Press.

Bloor, D. 1997. Wittgenstein, Rules and Institutions. London: Routledge.

Bloor, D. 1999. Anti-Latour. Studies in History and Philosophy of Science Part A 30 (1): $81-112$.

Bloor, D. 2004. Sociology of Scientific Knowledge. In Ilkka Niiniluoto, Matti Sintonen \& Jan Wolenski (eds.). Handbook of Epistemology, Dordrecht: Kluwer Academic. 919-962. 
Bloor, D. 2007. EPISTEMIC GRACE: Antirelativism as Theology in Disguise. Common Knowledge 13(2-3). 250-80

Bloor, D. 2008. Relativism at 30,000 Feet. In Knowledge as Social Order: Rethinking the Sociology of Barry Barnes. Edited by Massimo Mazzotti. Burlington, Vt.: Ashgate. 13-34.

Bloor, D. 2011. The Enigma of the Airfoil: Rival Theories in Aerodynamics, 1909-1930.

Chicago: The University of Chicago Press.

Bloor, D. 2014. "Reply to Christopher Norris". Journal of Critical Realism 13 (4): 399410.

Kemp, S. 2003. Toward a Monistic Theory of Science: The 'Strong Programme' Reconsidered. Philosophy of the Social Sciences 33 (3):311-338.

Kochan, J. 2008. Realism, Reliabilism, and the 'Strong Programme' in the Sociology of Scientific Knowledge. International Studies in the Philosophy of Science 22(1). 21-38

Kochan, J. 2010. Contrastive Explanation and the 'Strong Programme' in the Sociology of Scientific Knowledge. Social Studies of Science 40(1). 127-144

Kusch, M. 1999. Psychological Knowledge: A Social History and Philosophy. London and New York: Routledge.

Kusch, M. 2000. The sociology of philosophical knowledge. Dordrecht Boston: Kluwer Academic Publishers.

Kusch, M. 2002. Knowledge by Agreement: The Programme of Communitarian Epistemology. Oxford: Oxford University Press.

Lakatos, I. 1989. History of Science and Its Rational Reconstruction. in The Methodology of Scientific Research Programmes; Philosophical Papers. Vol. 1. Edited by John Worrall \& Gregory Corrie. Cambridge: Cambridge University Press.

Laudan, L. 1981. The Pseudo-Science of Science. Philosophy of the Social Sciences 11(2). 173-198 
Laudan, L. 1990. Demystifying underdetermination. In C. Wade Savage (ed.), Scientific Theories. Minneapolis, Minn.: University of Minnesota Press. 267-97.

Lewens, T. 2005. Realism and the Strong Program. The British Journal for the Philosophy of Science 56(3). 559-577.

Seidel, M. 2014. Epistemic Relativism: A Constructive Critique. Houndmills, Basingstoke: Palgrave Macmillan.

\section{- Acknowledgements}

The author would like to thank Stephen Kemp, Ebrahim Osooli, Rahman Sharifzadeh, Hossein Sheykh Rezaee and Mohammad Saleh Zarepour for their helpful discussions with him concerning the main argument of the paper. Two anonymous referees of this journal are also appreciated due to their comments on the previous draft that helped improve the paper.

\section{- Funding}

This work was supported by the Iranian Institute of Philosophy.

\section{- Disclosure statement}

No potential conflict of interest was reported by the author.

\section{- Biographical Note}

Shahram Shahryari is a research fellow at the Iranian Institute of Philosophy, science studies department, in Tehran. With a bachelor's degree in philosophy and a master's degree in philosophical logic, he wrote his doctoral thesis on relativism in the Strong Program. His current research interests include the sociology of scientific knowledge, contemporary relativism, rational disagreement and the later Wittgenstein. Shahram 
Shahryari has taught at Imam Sadiq University and Allameh Tabataba'i University in Tehran. 